\title{
Major Cytoplasmic Membrane Protein of Legionella pneumophila, a Genus Common Antigen and Member of the hsp 60 Family of Heat Shock Proteins, Induces Protective Immunity in a Guinea Pig Model of Legionnaires' Disease
}

\author{
Steven J. Blander and Marcus A. Horwitz \\ Division of Infectious Diseases, Department of Medicine, University of California at Los Angeles School of Medicine, Center for the \\ Health Sciences, Los Angeles, California 90024
}

\begin{abstract}
We have examined the capacity of the major cytoplasmic membrane protein (MCMP) of Legionella pneumophila, a genus common antigen and member of the hsp 60 family of heat shock proteins, to induce protective immunity in a guinea pig model of Legionnaires' disease. We purified MCMP to homogeneity from $L$. pneumophila by buffer extraction, ion-exchange chromatography, and molecular sieve chromatography.

Guinea pigs immunized with MCMP developed a strong cell-mediated immune response to the immunogen manifest by marked cutaneous delayed-type hypersensitivity. Guinea pigs immunized with MCMP and then challenged with a lethal aerosol dose of $L$. pneumophila exhibited a high level of protective immunity. Altogether, in four independent experiments, 55 of $64(86 \%)$ animals immunized three times with 0.6-40 $\mu \mathrm{g}$ MCMP including 11 of $11(100 \%)$ animals immunized three times with $40 \mu \mathrm{g}$ MCMP survived aerosol challenge with $L$. pneumophila compared with 1 of $29(3 \%)$ sham-immunized control animals $\left(P<0.0001\right.$, Cochran-Mantel-Haenszel $X^{2}$ statistic for pooled data).

To our knowledge, MCMP is the first member of the hsp 60 family of proteins shown to induce protective immunity to a microbial pathogen. MCMP has potential as a vaccine against Legionnaires' disease. Since MCMP is a genus common antigen, vaccination with a combination of MCMPs derived from different Legionella species has the potential of inducing protective immunity against all the major Legionella species causing human disease. (J. Clin. Invest. 1993. 91:717-723.) Key words: vaccine - immunoprotective determinants - cell-mediated immunity $\bullet$ intracellular parasitism • heat shock protein
\end{abstract}

Address correspondence and reprint requests to Dr. Horwitz, Division of Infectious Diseases, Department of Medicine, Center for the Health Sciences, 10833 Le Conte Ave., Los Angeles, CA 90024-1736. Dr. Blander's current address is Division of Infectious Diseases, Department of Medicine, University of Pittsburgh School of Medicine, Montefiore University Hospital, Pittsburgh, PA 15213.

Received for publication 31 March 1992 and in revised form 13 October 1992.

J. Clin. Invest.

(C) The American Society for Clinical Investigation, Inc.

$0021-9738 / 93 / 02 / 0717 / 07 \$ 2.00$

Volume 91, February 1993, 717-723

\section{Introduction}

Subunit vaccines are a major goal of modern vaccine research. Such vaccines, consisting of one or a few molecules or epitopes, offer several potential advantages over traditional whole cell vaccines, generally consisting of avirulent or killed microorganisms. First, by focusing the immune system on a few key immunoprotective determinants, rather than on a complex mix of a few relevant and many irrelevant molecular species, the subunit vaccine might attain greater protective efficacy. Second, by excluding molecular species capable of inducing suppression of an immune response, the subunit vaccine might allow the immune system to respond to immunoprotective moieties otherwise unable to induce protection in the midst of whole cell vaccines. Third, by being composed of a limited repertoire of molecular species, the subunit vaccine might be less likely to induce allergic or toxic reactions than whole cell vaccines.

Intracellular pathogens constitute a special challenge to the immune system and vaccine development. A successful vaccine must enable the host immune system to recognize infected host cells and mount an effective antimicrobial response against pathogens sequestered within them. The host immune system generally accomplishes this via cell-mediated immune mechanisms, such as those leading to the proliferation of antigen-specific lymphocytes capable of activating infected macrophages or exerting a cytotoxic effect against them. For this reason, microbial components that induce strong cell-mediated immune responses are potentially immunoprotective.

This laboratory has been investigating immunoprotective molecules of the intracellular pathogen Legionella pneumophila, the agent of Legionnaires' disease. Cell-mediated immunity plays a central role in host defense against $L$. pneumophila, whereas humoral immunity does not appear to play a significant role (1-4). In a previous study, we reported that the major secretory protein (MSP) ${ }^{1}$ of $L$. pneumophila induces cell-mediated immune responses and protective immunity against a lethal aerosol challenge with L. pneumophila in the guinea pig model of Legionnaires' disease (5). Interestingly, this molecule, although immunoprotective, is not a virulence determinant in the guinea pig model (6). This demonstrates that, in the case of an intracellular pathogen, vaccinogens can induce

1. Abbreviations used in this paper: CYEA, charcoal yeast extract agar; MCMP, major cytoplasmic membrane protein; MSP, major secretory protein. 
protective immune responses that function in ways other than by neutralizing virulence determinants, such as by enhancing the capacity of the immune system to detect and respond effectively against infected host cells. The major secretory protein is capable of inducing protective immunity across at least some serogroups of $L$. pneumophila, but not necessarily across species in the family Legionellacea, including some that cause pneumonia (7). The major secretory protein also does not induce protection against strains of $L$. pneumophila and species of Legionella that do not secrete the protein (7). These limitations of the major secretory protein prompted a search for other immunoprotective molecules of $L$. pneumophila.

Subsequently, we demonstrated that L. pneumophila membranes induce protective immunity independent of the major secretory protein ( 8 ). However, the identity of immunoprotective components of the membranes remained to be determined. To identify such components, we focused our attention on native membrane antigens recognized by immune lymphocytes. Using the $T$ cell Western blot technique $(9,10)$, we noted in preliminary studies that immune lymphocytes from guinea pigs immunized with a sublethal dose of aerosolized $L$. pneumophila responded more strongly than control lymphocytes to a protein in the region of the $65-\mathrm{kD}$ major cytoplasmic membrane protein (MCMP). We also determined that guinea pigs immunized with purified MCMP, but not sham-immunized control animals, developed a strong cell-mediated immune response to the protein, manifest by cutaneous delayedtype hypersensitivity. These findings suggested that MCMP may have immunoprotective potential.

MCMP was so designated in an early study from this laboratory that demonstrated that this molecule was the major protein species in the cytoplasmic membrane fraction isolated from cell envelopes of $L$. pneumophila by isopycnic centrifugation (11). More recently, immunoelectron microscopy studies in this laboratory using monospecific affinity-purified antiMCMP antibody have demonstrated that the great majority of MCMP in the bacterial cell is associated with the bacterial membrane of L. pneumophila, whereas the amount in the cytoplasm is minimal (Clemens, D. L., E. Shang, and M. A. Horwitz, unpublished data). Our early study also showed that MCMP was the major protein species of L. pneumophila recognized by antibody in convalescent sera of patients recovered from Legionnaires' disease (11). Subsequently, studies by other investigators have demonstrated that this protein is a genus common antigen and a member of the hsp 60 family of heat-shock proteins (12-14).

In the present study, we have purified MCMP and examined its immunoprotective capacity. We shall demonstrate that immunization with MCMP induces protective immunity against lethal aerosol challenge with $L$. pneumophila.

\section{Methods}

Media. Albumin yeast extract broth, and egg yolk buffer with or without $1 \%$ BSA (Miles Laboratories Inc., Naperville, IL) were prepared as previously described (15). RPMI 1640 with L-glutamine (Gibco Laboratories, Grand Island, NY) was mixed with penicillin $(100 \mathrm{U} / \mathrm{ml})$ and streptomycin ( $100 \mu \mathrm{g} / \mathrm{ml})$ (Gibco Laboratories).

Agar. Modified charcoal yeast extract agar (CYEA) was prepared as described (15). Modified CYEA without cysteine and tryptic soy agar with $5 \%$ sheep blood were used to assay for contaminating bacteria.
Bacteria. L. pneumophila, Philadelphia 1 strain (serogroup 1), was grown in embryonated hens' eggs, harvested, tested for viability and the presence of contaminating bacteria, passed one time only on CYEA, washed with egg yolk buffer, flash frozen in aliquots of $10^{11} \mathrm{CFU} / \mathrm{ml}$, and stored at $-70^{\circ} \mathrm{C}(15)$. Before use in the aerosol inoculation system, a stock preparation of bacteria was diluted in EYB to the desired concentration.

Purification of MCMP. L. pneumophila was grown on CYEA and harvested into an extraction buffer consisting of $0.05 \mathrm{M}$ Tris, $0.01 \mathrm{M}$ EDTA, $0.02 \mathrm{M}$ MgSO4, pH 8.0, 0.0005\% DNase, and 0.024\% lysozyme. The suspension was shaken at $100 \mathrm{rpm}$ for $1 \mathrm{~h}$ at room temperature and centrifuged at $16,000 \mathrm{~g}$ for $10 \mathrm{~min}$ at $4^{\circ} \mathrm{C}$ to pellet the bacteria. The supernate, containing extracted MCMP and other molecules, was filtered through $0.45-\mu \mathrm{m}$ low protein binding filters (Tuffryn; Gelman Sciences, Inc., Ann Arbor, MI) to remove residual bacteria. The pellet was resuspended in extraction buffer and the above procedure repeated once. The filtrates from the two extraction procedures were combined and applied to a $2.5 \times 13-\mathrm{cm}$ Sepharose CL-6B column (Pharmacia Fine Chemicals, Piscataway, NJ), and a gradient of $0.1-0.25 \mathrm{M} \mathrm{NaCl}$ in $0.05 \mathrm{M}$ Tris containing $0.01 \mathrm{M}$ EDTA was applied at a flow rate of $10 \mathrm{ml} / \mathrm{h}$ using a gradient maker (Pharmacia Fine Chemicals) with 2.5 bed volumes in each chamber. Fractions containing the 65-kD MCMP, eluting at $0.17 \mathrm{M} \mathrm{NaCl}$, were identified by SDS-PAGE (16) and pooled.

In initial studies, MCMP was purified in the final step by affinity chromatography using monospecific rabbit or guinea pig anti-MCMP antibody eluted from strips of transfer membranes (Immobilon; Millipore Corp., Bedford, MA), to which electrophoretically purified MCMP was transferred. In later studies; MCMP was purified in the final step by a simpler procedure, molecular sieve chromatography, as follows: Ion exchange purified MCMP was concentrated (Centriprep 30; Amicon, Beverly, MA), dialyzed against $0.05 \mathrm{M}$ Tris, $0.01 \mathrm{M}$ EDTA, and $0.1 \mathrm{M} \mathrm{NaCl}$, pH 8.0, and applied to a $2.6 \times 70-\mathrm{cm}$ Sephacryl S- $400 \mathrm{HR}$ column. The column was eluted with the same buffer at a flow rate of $240 \mathrm{ml} / \mathrm{h}$. Fractions containing MCMP were pooled, concentrated with Centriprep 30, dialyzed against PBS, and stored at $4^{\circ} \mathrm{C}$ under nitrogen until use.

Mass and purity of MCMP. The mass of MCMP was measured with a bicinchoninic acid protein assay (Pierce Chemical Co., Rockford, IL) using BSA as a standard. The purity of MCMP was assessed by SDS-PAGE by applying $10 \mu \mathrm{g}$ of purified MCMP to a $12.5 \%$ gel and staining with Coomassie brilliant blue $\mathrm{R}$ and by $\mathrm{NH}_{2}$-terminal sequencing. Protein sequencing was performed at the University of California at Los Angeles Protein Microsequencing Facility.

Localization of MCMP in the L. pneumophila envelope. L. pneumophila membranes were prepared as previously described $(8,11)$. Briefly, whole $L$. pneumophila cells were converted to spheroplasts by treatment with lysozyme and EDTA, the spheroplasts were lysed osmotically, and the cell envelopes were resolved into inner and outer membrane fractions by isopycnic ( sucrose density gradient) centrifugation (11). The membrane fractions were subjected to SDS-PAGE and analyzed by immunoblot analysis as described $(8,17)$. For immunoblot analysis, monospecific anti-MCMP antibody was prepared by immunizing rabbits with purified MCMP, collecting the antiserum, binding the anti-MCMP antibody to purified MCMP that had been subjected to SDS-PAGE and transferred to Immobilon transfer membranes (Millipore Corp.), and eluting the monospecific antibody from the membranes. The second antibody was alkaline phosphataseconjugated goat anti-rabbit IgG (Sigma Chemical Co., St. Louis, MO), and the enzyme substrate solution used for visualization consisted of nitroblue tetrazolium and 5-bromo-4-chloro-indolyl-phosphate in anhydrous dimethyl formamide in $0.05 \mathrm{M}$ Tris and $0.003 \mathrm{M} \mathrm{MgCl}_{2}, \mathrm{pH}$ 10 , as described (8).

Animals. Male Hartley strain guinea pigs weighing 250-300 $\mathrm{g}$ (Simonson Laboratories, Gilroy, CA), were cared for as previously described (18). They were observed in the vivarium for $1 \mathrm{wk}$ before 
challenge with $L$. pneumophila to ensure that they were healthy. No illnesses or deaths occurred in the guinea pigs before challenge.

Immunization of guinea pigs with MCMP. Guinea pigs were immunized with MCMP three times at $\geq 3$ wk intervals. MCMP was dialyzed in PBS and mixed 1:1 in CFA for the first injection, and in incomplete Freund's adjuvant for the second and third injections. The injection sites of the guinea pigs were washed with $70 \%$ ethanol and the animals were injected subcutaneously with $40,10,2.5$, or $0.6 \mu \mathrm{g}$ of MCMP. Control animals were sham immunized at the same time with normal saline in CFA (first injection) or incomplete Freund's adjuvant (subsequent injections).

Cutaneous delayed-type hypersensitivity assay. Guinea pigs were shaved over the back and flank and administered 0,1 , or $10 \mu \mathrm{g}$ MCMP in a total volume of $100 \mu \mathrm{l}$ PBS intradermally. The diameters or erythema and induration were measured $24 \mathrm{~h}$ later.

Protective immunity. Guinea pigs were challenged by exposure to aerosols containing wild-type $L$. pneumophila in an aerosol chamber described in detail in a previous study (4). Guinea pigs were challenged 3-5 wk after immunization with a $100 \%$ lethal dose of aerosolized wild-type $L$. pneumophila. This dose, which was generated from a 10$\mathrm{ml}$ suspension of wild-type $L$. pneumophila containing $1-2 \times 10^{8}$ $\mathrm{CFU} / \mathrm{ml}$, was the lowest dose that consistently resulted in the death of nonimmunized guinea pigs, as previously described (4). After challenge, animals were held in filter-top cages for $10 \mathrm{~d}$. During this time they were observed for signs of illness, and survival was quantitated. Differences in survival between immunized and control animals within experiments were evaluated by computing exact permutational $P$ values (StatXact software; Cytel Corp., Cambridge, MA). For pooled data, differences in survival between immunized and control animals were evaluated by the Cochran-Mantel-Haenszel $\chi^{2}$ statistic.

\section{Results}

Purification of MCMP. We initially purified MCMP by a three-step process involving buffer extraction from whole $L$. pneumophila, ion-exchange chromatography, and affinity chromatography. SDS-PAGE analysis of the purified MCMP yielded a single band of apparent molecular mass of $60-65 \mathrm{kD}$, suggesting a high degree of purity, and this material was used to immunize animals in initial challenge experiments (experiments $\mathrm{A}$ and $\mathrm{B}$, Table I). Subsequently, $\mathrm{NH}_{2}$-terminal sequence analysis of MCMP purified by affinity chromatography in the final step revealed the presence of serum albumin in the preparation. Although the presence of albumin was unlikely to influence the results of the challenge experiments in a qualitative way, it complicated the determination of MCMP concentration in the immunizing dose. We therefore developed an alternative purification procedure using molecular sieve chromatography rather than affinity chromatography in the final step of purification. The purified MCMP obtained by this simpler procedure also exhibited a single band of apparent molecular mass of 60-65 kD on SDS-PAGE analysis (Fig. 1, lane $E$ ), suggesting that it was $>99 \%$ pure. Moreover, $\mathrm{NH}_{2}$-terminal sequence analysis of this preparation revealed a pure protein and the sequence of the $40 \mathrm{NH}_{2}$-terminal amino acids exactly matched the deduced sequence derived from the published nucleotide sequence of $\operatorname{MCMP}(19,20)$, otherwise known as the $60-\mathrm{kD}$ common antigen and member of the hsp 60 heat shock protein family. We repeated the challenge experiments (experiments $\mathrm{C}$ and $\mathrm{D}$, Table $\mathrm{I}$ ) using this preparation of purified MCMP.

Localization of MCMP to the cytoplasmic membrane. The fact that milligram quantities of MCMP were purified from a
Table I. Immunization of Guinea Pigs with MCMP Induces Protective Immunity against Lethal Aerosol Challenge with Legionella pneumophila

\begin{tabular}{|c|c|c|c|c|}
\hline Experiment & $\begin{array}{l}\text { Status of } \\
\text { guinea pigs }\end{array}$ & $\begin{array}{l}\text { Immunizing } \\
\text { dose }\end{array}$ & $\begin{array}{l}\text { Number of guinea } \\
\text { pigs surviving per } \\
\text { number challenged } \\
\text { (percent survival) }\end{array}$ & $P^{*}$ \\
\hline \multirow[t]{3}{*}{ A } & $\begin{array}{l}\text { Control } \\
\text { Immunized }\end{array}$ & 0 & $0 / 6(0)$ & \\
\hline & (MCMP) & $10-40^{\ddagger}$ & $4 / 6(67)$ & 0.06 \\
\hline & $\begin{array}{c}\text { Immunized } \\
\text { (Sublethal } \\
\text { infection) }\end{array}$ & & $4 / 4(100)$ & 0.005 \\
\hline \multirow[t]{2}{*}{ B } & Control & 0 & $0 / 7(0)$ & \\
\hline & $\begin{array}{l}\text { Immunized } \\
\text { (MCMP) }\end{array}$ & $10-40^{\ddagger}$ & $6 / 6(100)$ & 0.0006 \\
\hline \multirow[t]{7}{*}{ C } & $\begin{array}{l}\text { Control } \\
\text { Immunized }\end{array}$ & 0 & $1 / 8(13)$ & \\
\hline & (MCMP) & 40 & $5 / 5(100)$ & 0.005 \\
\hline & Immunized & & & \\
\hline & (MCMP) & 10 & $4 / 6(67)$ & 0.09 \\
\hline & $\begin{array}{c}\text { Immunized } \\
\text { (MCMP) }\end{array}$ & 2.5 & 6/7 (86) & 0.01 \\
\hline & Immunized & & & \\
\hline & (MCMP) & 0.6 & $7 / 7(100)$ & 0.001 \\
\hline \multirow[t]{7}{*}{ D } & Control & 0 & $0 / 8(0)$ & \\
\hline & $\begin{array}{l}\text { Immunized } \\
(\mathrm{MCMP})\end{array}$ & 40 & $6 / 6(100)$ & 0.003 \\
\hline & Immunized & & & \\
\hline & (MCMP) & 10 & $6 / 6(100)$ & 0.003 \\
\hline & Immunized & & & \\
\hline & (MCMP) & 2.5 & $7 / 7(100)$ & 0.002 \\
\hline & $\begin{array}{l}\text { Immunized } \\
\text { (MCMP) }\end{array}$ & 0.6 & $4 / 8(50)$ & 0.08 \\
\hline \multirow[t]{3}{*}{ Total } & Control & 0 & $1 / 29(3)$ & \\
\hline & Immunized & $0.6-40$ & $55 / 64(86)$ & $<0.0001$ \\
\hline & Immunized & 40 & $11 / 11(100)$ & $<0.0001$ \\
\hline
\end{tabular}

In four independent experiments, guinea pigs were immunized subcutaneously three times with doses of MCMP ranging from 0.6 to 40 $\mu \mathrm{g}$, as indicated, or sham immunized. 3-5 wk later, the animals were challenged with one lethal dose of $L$. pneumophila, and survival was quantitated. ${ }^{*}$ Exact permutational $P$ values for immunized versus control animals in individual experiments (experiments A-D). Cochran-Mantel-Haenszel $\chi^{2}$ statistic for pooled data. ${ }^{\ddagger}$ The MCMP preparation used in experiments $A$ and $B$ contained a small amount of serum albumin; the amount of MCMP in the immunizing dose was between 10 and $40 \mu \mathrm{g}$ in these experiments.

small number of plates of bacteria implied that MCMP was one of the three major proteins of L. pneumophila cells. Only one of these proteins, the major protein species in the cytoplasmic membrane, has a molecular weight similar to or even near that of purified MCMP. To confirm the identity of MCMP as this cytoplasmic membrane protein, we examined purified MCMP and purified $L$. pneumophila cytoplasmic and outer membranes by SDS-PAGE and immunoblot analysis. Purified MCMP migrated to the same extent as the major species of the cytoplasmic membrane on SDS-PAGE gels (Fig. $2 A$ ). Moreover, on immunoblot analysis of the cytoplasmic membrane (Fig. $2 B$, lane $C$ ), monospecific anti-MCMP antibody raised against purified MCMP specifically recognized a major protein of the same apparent molecular weight as the major protein species of the cytoplasmic membrane on a duplicate lane of the 


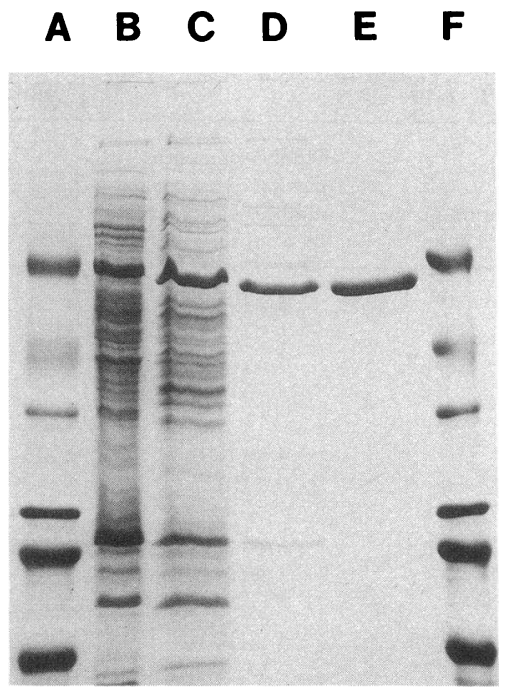

hyde-3-phosphate dehydrogenase, 36,000; carbonic anhydrase, 29,000; trypsinogen, 24,000; and trypsin inhibitor, 20,100).

gel (Fig. $2 B$, lane $B$ ). Taken together, these data demonstrate that the purified protein was the same as the major protein species of the cytoplasmic membrane, previously designated MCMP.

Guinea pigs immunized with MCMP develop a cutaneous delayed-type hypersensitivity response to MCMP. To determine if MCMP-immunized guinea pigs develop a cell-mediated immune response to the immunogen, we skin-tested the animals after immunization. In three independent experiments, MCMP-immunized animals consistently exhibited stronger skin test responses than sham-immunized control guinea pigs, with markedly greater erythema and induration (Table II). The mean extent of erythema in MCMP-immunized animals was 1.8 times to infinitely greater than that in sham-immunized animals. With one exception ( the lower dose tested in experiment $C$ ), the mean extent of induration was 3.7 times to infinitely greater than that in sham-immunized controls. In the one experiment in which animals were immunized with different doses of MCMP (ranging from 0.6 to $40 \mu \mathrm{g}$ ), the MCMP-immunized animals exhibited a clear-cut dose-dependent response to MCMP on skin testing; i.e., the higher the immunizing dose, the greater the extent of erythema and induration in response to MCMP (Table II, experiment B).

Guinea pigs immunized with MCMP are protected against lethal aerosol challenge with L. pneumophila. To determine if guinea pigs immunized with MCMP are protected against lethal aerosol challenge, we immunized guinea pigs three times with $0.6-40 \mu \mathrm{g}$ of MCMP, and 3-5 wk later, we challenged MCMP-immunized and sham-immunized animals with a lethal aerosol dose of $L$. pneumophila. In four independent experiments, guinea pigs immunized with MCMP demonstrated significantly greater survival than control animals ( Table I). Overall, 55 of 64 ( $86 \%$ ) animals immunized with $0.6-40$ $\mu \mathrm{g}$ doses of MCMP survived, compared with 1 of 29 (3\%) control animals $\left(P<0.0001\right.$, Cochran-Mantel-Haenszel $\chi^{2}$ statistic for pooled data). Of animals immunized with $40 \mu \mathrm{g}$ MCMP, the highest dose tested, 11 of $11(100 \%)$ survived chal- lenge compared with 1 of $16(6 \%)$ control animals in these experiments (experiments $C$ and $D$, Table $I)(P<0.0001)$. In experiment A (Table I), as a positive control, one group of animals was immunized with a sublethal dose of $L$. pneumophila, previously shown to induce protective immunity (4). These animals exhibited a higher level of protective immunity (100\%) than MCMP-immunized animals (67\%) but this difference was not statistically significant. In subsequent experiments (experiments B-D, Table I), animals immunized with the higher doses of MCMP also exhibited $100 \%$ protection.

Immunized animals first exhibited signs of illness including decreased activity and respiratory distress $1 \mathrm{~d}$ after challenge, but most then recovered. This response in immunized animals was clearly dose-dependent $(40>10>2.5>0.6 \mu \mathrm{g}$ immunizing dose) in the two experiments (experiments $C$ and $D$, Table I) in which animals were immunized with different doses of MCMP. Sham-immunized control animals had a later onset of signs of illness, usually 1-2 d after challenge, but they did not

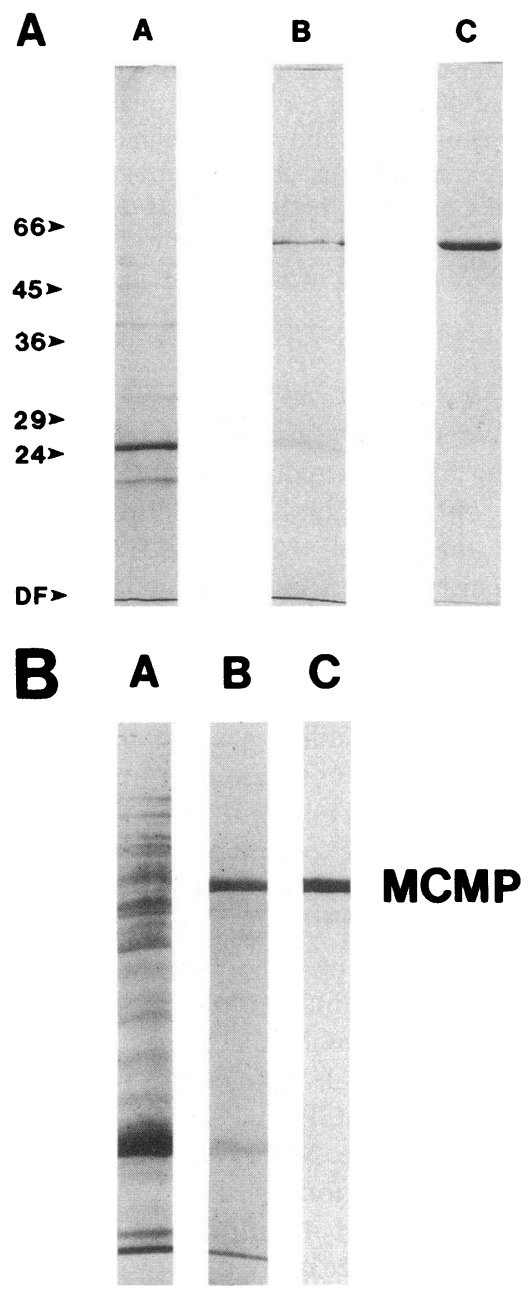

Figure 2. SDS-PAGE and immunoblot analysis of purified MCMP and $L$. pneumophila cytoplasmic and outer membranes. MCMP was purified by buffer extraction, ion-exchange chromatography, and molecular sieve chromatography, and $L$. pneumophila cell envelopes were isolated and resolved into cytoplasmic and outer membrane fractions, as described in the text. $(A)$ The three preparations were subjected to SDS-PAGE and stained with coomassie brilliant blue $\mathbf{R}$. The outer membrane (lane $A$ ) contained a major protein of apparent molecular mass of $28 \mathrm{kD}$. The cytoplasmic membrane (lane $B$ ) contained a single major protein species of apparent molecular mass of $60 \mathrm{kD}$. Purified MCMP (lane C) migrated to the same extent as the major protein in the cytoplasmic membrane. Molecular mass standards are in kilodaltons. $D F$, dye front. (B) L. pneumophila outer membranes (lane $A$ ) and cytoplasmic membranes (lanes $B$ and $C$ ) were subjected to SDS-PAGE and electrophoretically transferred to nitrocellulose membranes. Lanes $A$ and $B$ were stained with amido black. Lane $C$ was incubated with monospecific anti-MCMP antibody and the bound antibody visualized using alkaline phosphatase-conjugated goat anti-rabbit IgG as described in the text. 
Table II. Guinea Pigs Immunized with MCMP Exhibit Cutaneous Delayed-type Hypersensitivity to MCMP

\begin{tabular}{|c|c|c|c|c|c|c|c|}
\hline \multirow[b]{2}{*}{ Experiment } & \multirow{2}{*}{$\begin{array}{c}\text { Status of } \\
\text { guinea pigs }\end{array}$} & \multirow{2}{*}{$\begin{array}{l}\text { Immunizing } \\
\text { dose }\end{array}$} & \multirow{2}{*}{$\begin{array}{l}\text { Number of } \\
\text { guinea pigs }\end{array}$} & \multicolumn{2}{|c|}{$\begin{array}{c}\text { Extent of skin reaction in } \\
\text { response to } 1 \mu \mathrm{g} \text { MCMP } \\
\text { (mean } \pm \mathrm{SE} \text { ) }\end{array}$} & \multicolumn{2}{|c|}{$\mathrm{SI}^{*}$} \\
\hline & & & & Erythema & Induration & Erythema & Induration \\
\hline & & $\mu g$ & & & & & \\
\hline \multirow[t]{2}{*}{ A } & Immunized & 40 & 6 & $13.3 \pm 1.2$ & $8.5 \pm 0.8$ & 1.8 & 3.7 \\
\hline & Control & 0.0 & 3 & $7.3 \pm 2.7$ & $2.3 \pm 1.5$ & & \\
\hline \multirow[t]{5}{*}{ B } & Immunized & 40 & 5 & $17.8 \pm 1.5$ & $7.2 \pm 1.5$ & $\infty$ & $\infty$ \\
\hline & Immunized & 10 & 6 & $10.3 \pm 0.9$ & $5.8 \pm 0.9$ & $\infty$ & $\infty$ \\
\hline & Immunized & 2.5 & 6 & $8.8 \pm 0.5$ & $4.0 \pm 1.1$ & $\infty$ & $\infty$ \\
\hline & Immunized & 0.6 & 4 & $6.3 \pm 0.5$ & $0.0 \pm 0$ & $\infty$ & - \\
\hline & Control & 0.0 & 3 & $0.0 \pm 0$ & $0.0 \pm 0$ & & \\
\hline \multirow[t]{3}{*}{$\mathrm{Cl}$} & Immunized & 40 & 20 & $9.2 \pm 0.4$ & $0.8 \pm 0.4$ & 4.0 & 0.9 \\
\hline & Control & 0.0 & 9 & $2.3 \pm 0.8$ & $0.9 \pm 0.6$ & & \\
\hline & & & & \multicolumn{2}{|c|}{$\begin{array}{c}\text { Extent of skin reaction in } \\
\text { response to } 10 \mu \mathrm{g} \text { MCMP } \\
\text { (Mean } \pm \text { SE) }\end{array}$} & & \\
\hline \multirow[t]{2}{*}{$\mathrm{C} 2$} & Immunized & 40 & 20 & $13.9 \pm 0.5$ & $5.8 \pm 0.8$ & 2.0 & 7.3 \\
\hline & Control & 0.0 & 9 & $6.8 \pm 0.7$ & $0.8 \pm 0.6$ & & \\
\hline
\end{tabular}

In three independent experiments, guinea pigs were immunized subcutaneously three times with $0.6-40 \mu \mathrm{g}$ MCMP, as indicated, or sham immunized. 3-5 wk later, the animals were skin tested with an intradermal dose of $1 \mu \mathrm{g}$ MCMP (experiments A and B) or both 1 and $10 \mu \mathrm{g}$ MCMP (experiment C). The extent of erythema and induration at skin test sites was measured $24 \mathrm{~h}$ later. Neither immunized nor control animals developed erythema or induration in response to the PBS buffer in which the MCMP skin test antigen was diluted. ${ }^{*}$ SI, stimulation index $=$ (mean skin reactivity of immunized guinea pigs)/(mean skin reactivity of control guinea pigs).

recover. All animals surviving $10 \mathrm{~d}$ after challenge recovered fully from earlier signs of disease.

In experiments $\mathrm{C}$ and $\mathrm{D}$ ( Table $\mathrm{I}$ ), in which animals were immunized with doses of MCMP ranging from 0.6-40 $\mu \mathrm{g}$, even the lowest immunizing dose was highly protective against death. However, protection against illness in these experiments was clearly dose-dependent. All animals immunized with 0.6 or $2.5 \mu \mathrm{g}$ of MCMP exhibited marked respiratory distress on days 3-8 after challenge, whereas animals immunized with 10 or $40 \mu \mathrm{g}$ MCMP exhibited little or no respiratory signs of illness during this time frame.

\section{Discussion}

This study demonstrates that MCMP induces protective immunity in the guinea pig model of Legionnaires' disease. MCMP is the first membrane molecule of $L$. pneumophila shown to have this property. Whether the L. pneumophila membrane contains other immunoprotective molecules remains to be determined.

An early study of $L$. pneumophila proteins from this laboratory revealed that the bacterium contains three major proteins on SDS-PAGE analysis of apparent molecular masses of 28 , 45 , and $65 \mathrm{kD}$ (11). Separation of the cytoplasmic and outer membranes of $L$. pneumophila by isopycnic centrifugation over sucrose density gradients showed that the $28-\mathrm{kD}$ protein was the major protein species of the outer membrane, and the $65-\mathrm{kD}$ protein was the major protein species of the cytoplasmic membrane (11). These proteins were therefore designated major outer membrane protein (MOMP) and MCMP, respec- tively (11). The major outer membrane protein was subsequently found to be a porin (21). The role of the MCMP in bacterial physiology remains unknown.

The MCMP, which in various studies has been referred to as having an apparent molecular mass of $58,60,63$, and $65 \mathrm{kD}$, has been found to have several interesting characteristics. Gabay and Horwitz found that it is the most prominent protein of L. pneumophila serogroup 1 (Philadelphia 1 strain) recognized by antibody in the convalescent sera of patients recovered from Legionnaires' disease (11). Subsequently, Sampson et al. confirmed this observation and demonstrated that MCMP was a genus common antigen (12). They showed that all sera from patients with culture-positive legionella infection contained antibody that recognized this antigen, including sera from patients infected with $L$. pneumophila serogroups 1-8 and six other species of Legionella (12). Pau et al. extended these observations by demonstrating that $L$. pneumophila Philadelphia 1 MCMP was recognized by antibody in rabbit immune serum prepared against each of 23 Legionella species (13). Lema et al. showed later that MCMP was a heat-shock protein recognized by antibody to the $E$. coli GroEL protein, a major heat-shock protein of this bacterium and a member of the widely distributed hsp 60 family of heat-shock or stress proteins (14). Hoffman et al. cloned the gene encoding MCMP, which they designated htpB, and demonstrated that expression of the protein in $E$. coli was temperature-dependent (22). Subsequently, Sampson et al. and Hoffman et al. sequenced the gene and showed that it was highly homologous with the $E$. coli GroEL protein, the 65-kD proteins of Mycobacterium tuberculosis and Mycobacterium leprae, the $60-\mathrm{kD}$ protein of Coxiella burnetii, and 
the 58-kD protein of Chlamydia species $(19,20)$. The gene encoded a mature protein of 547 amino acids, which Sampson et al. determined had a computed molecular mass of 57,952 D (19).

As other species of Legionella also contain this genus common antigen, vaccination with the MCMP molecules derived from these species may similarly induce protective immunity against the homologous species. Thus, a combination of MCMP molecules from different legionella species has the potential of inducing protective immunity against all legionella species that are major causes of human disease. Furthermore, because MCMP is a genus common antigen that may contain shared $\mathrm{T}$ cell as well as B cell epitopes, MCMP may induce protective immunity across species of Legionella; i.e., MCMP from some species of Legionella may protect against other species of Legionella in addition to the homologous species.

MCMP is the second protein molecule of L. pneumophila that we have found to be immunoprotective by itself. As noted in the introduction, MSP is also highly immunoprotective. As immunogens, both MCMP and MSP may have advantages in different settings, and a vaccine combining them might be more efficacious than one containing only one of the proteins.

As noted above, MCMP is a heat-shock protein and member of the hsp 60 family of such proteins. Heat-shock proteins including the hsp 60 family have frequently been found to be immunodominant molecules of intracellular pathogens. Thus, for example, the $65-\mathrm{kD}$ proteins of $M$. tuberculosis and $M$. leprae are major $\mathrm{T}$ cell and $\mathrm{B}$ cell antigens $(23,24)$ and the $57-\mathrm{kD}$ heat shock protein of Chlamydia trachomatis elicits a strong humoral immune response in human infection (25) and cell-mediated inflammatory response in a guinea pig model of chlamydial ocular infection (26). To our knowledge, MCMP is the first member of the hsp 60 family shown to induce protective immunity (27).

The hsp 60 or GroEL family of heat shock proteins is a very conserved group and a high level of homology (50-60\% sequence identity) exists between human and bacterial hsp 60 proteins, including Legionella hsp 60 protein $(19,20,27,28)$. This has raised the question as to whether microbial hsp 60 proteins might play a role in autoimmune disease. In support of this idea, $T$ cells reactive with the mycobacterial hsp 65-kD protein, a member of the hsp 60 family, have been found in the synovial fluid of patients with rheumatoid arthritis and reactive post-infectious arthritis $(29,30)$. Also, in the rat model of adjuvant-induced arthritis, a $\mathrm{T}$ cell clone capable of causing severe arthritis upon transfer to heavily irradiated recipients recognizes an epitope of the mycobacterial hsp $65-\mathrm{kD}$ protein $(31$, 32). However, $T$ cells reactive to self epitopes of the hsp 60 protein and antibody to conserved epitopes of hsp 60 protein have been identified in normal healthy individuals $(33,34)$, indicating that the mere existence of hsp 60 reactive $T$ and $B$ cell clones in an individual is not necessarily associated with disease.

While $T$ cells reactive with hsp 60 proteins may be involved in autoimmune disease, there is no evidence that immunization with purified hsp 60 proteins induces chronic autoimmune disease. In fact, to the contrary, there is evidence that immunization with these proteins protects against autoimmune disease. Pretreatment of rats with a mycobacterial hsp 65-kD protein protects against adjuvant-induced arthritis and against streptococcal cell wall-induced $\mathrm{T}$ cell dependent polyar- thritis $(31,35,36)$. Immunization of nonobese diabetic mice with the hsp 65 of $M$. tuberculosis protects against spontaneous autoimmune insulin-dependent diabetes mellitus (37).

Our finding that MCMP induces a cell-mediated immune response and protective immunity against $L$. pneumophila raises the question as to how this molecule is released intracellularly for subsequent processing and presentation by infected host cells, thus enabling immune lymphocytes to exert an antimicrobial effect against intracellular bacteria. The mechanism by which $L$. pneumophila releases MSP appears relatively straightforward, as MSP is a secreted protein (38). Indeed, immunoelectron microscopy and immunohistologic studies have demonstrated that $L$. pneumophila releases MSP into its phagosome in infected human monocytes in vitro, and infected guinea pig alveolar macrophages in vivo $(38,39)$. Recent studies in this laboratory have demonstrated that L. pneumophila grown in broth culture releases abundant amounts of newly synthesized MCMP. Moreover, preliminary immunoelectron microscopy studies indicate that $L$. pneumophila releases large amounts of MCMP into its phagosome in infected human monocytes, apparently by membrane blebbing (Clemens, D. L., E. Shang, and M. A. Horwitz, unpublished data). Thus, two key features of MSP and MCMP that may underlie their immunoprotective potency are that $(a)$ they are major proteins of $L$. pneumophila; and (b) they are released into the phagosome of L. pneumophila in infected host mononuclear phagocytes.

\section{Acknowledgments}

We are grateful to Ms. Theresa Tuazon and Ms. Barbara Jane Dillon for outstanding technical assistance.

This work was supported by grant AI-22421 from the National Institutes of Health. Dr. Horwitz is the Gordon MacDonald Scholar at the University of California, Los Angeles. During the time this work was performed, Dr. Blander was supported by National Institutes of Health Training Grant AI-07126.

\section{References}

1. Horwitz, M. A. 1983. Cell-mediated immunity in Legionnaires' disease. $J$. Clin. Invest. 71:1686-1697.

2. Horwitz, M. A., and S. C. Silverstein. 1981. Activated human monocytes inhibit the intracellular multiplication of Legionnaires' disease bacteria. J. Exp. Med. 154:1618-1635.

3. Nash, T. W., D. M. Libby, and M. A. Horwitz. 1984. Interaction between the Legionnaires' disease bacterium Legionella pneumophila and human alveolar macrophages: influence of antibody, lymphokines, and hydrocortisone. J. Clin. Invest. 74:771-782.

4. Breiman, R. F., and M. A. Horwitz. 1987. Guinea pigs sublethally infected with aerosolized Legionella pneumophila develop humoral and cell-mediated immune responses and are protected against lethal aerosol challenge: a model for studying host defense against lung infections caused by intracellular pathogens. $J$. Exp. Med. 164:799-811.

5. Blander, S. J., and M. A. Horwitz. 1989. Vaccination with the major secretory protein of Legionella pneumophila induces cell-mediated and protective immunity in a guinea pig model of Legionnaires' disease. J. Exp. Med. 169:691705.

6. Blander, S. J., L. Szeto, H. A. Shuman, and M. A. Horwitz. 1990. An immunoprotective molecule, the major secretory protein of Legionella pneumophila, is not a virulence factor in a guinea pig model of Legionnaires' disease: $J$. Clin. Invest. 86:817-824.

7. Blander, S. J., and M. A. Horwitz. 1991. Vaccination with the major secretory protein of Legionella induces humoral and cell-mediated immune responses and protective immunity across different serogroups of Legionella pneumophila and different species of Legionella. J. Immunol. 147:285-291.

8. Blander, S. J., and M. A. Horwitz. 1991. Vaccination with Legionella 
pneumophila membranes induces cell-mediated and protective immunity in a guinea pig model of Legionnaires' disease. Protective immunity independent of the major secretory protein of Legionella pneumophila. J. Clin. Invest. 87:10541059.

9. Young, D. B., and J. R. Lamb. 1986. T lymphocytes respond to solid phase antigen: a novel approach to the molecular analysis of cellular immunity. Immunology. 59:167-171.

10. Abou-Zeid, C. E. Filley, J. Steele, and G. A. W. Rook. 1987. A simple new method for using antigens separated by polyacrylamide electrophoresis to stimulate lymphocytes in vitro after converting bands cut from Western blots into antigen-bearing particles. J. Immunol. Methods. 98:5-10.

11. Gabay, J. E., and M. A. Horwitz. 1985. Isolation and characterization of the cytoplasmic and outer membranes of the Legionnaires' disease bacterium Legionella pneumophila. J. Exp. Med. 161:409-422.

12. Sampson, J. S., B. B. Plikaytis, and H. W. Wilkinson. 1986. Immunologic response of patients with legionellosis against major protein-containing antigens of Legionella pneumophila serogroup 1 as shown by immunoblot analysis. $J$. Clin. Microbiol. 23:92-99.

13. Pau, C. P., B. B. Plikaytis, G. M. Carlone, and I. M. Warner. 1988. Purification, partial characterization, and seroreactivity of a genus-wide 60-kilodalton Legionella protein antigen. J. Clin. Microbiol. 26:67-71.

14. Lema, M. W., A. Brown, C. A. Butler, and P. S. Hoffman. 1988. Heatshock response in Legionella pneumophila. Can. J. Microbiol. 34:1148-1153.

15. Horwitz, M. A., and S. C. Silverstein. 1980. Legionnaires' disease bacterium (Legionella pneumophila) multiplies intracellularly in human monocytes. J. Clin. Invest. $66: 441-450$.

16. Laemmli, V. K. 1970. Cleavage of structural proteins during the assembly of the head of bacteriophage T4. Nature (Lond.). 227:680-685.

17. Towbin, H., T. Staehlin, and J. Gordon. 1979. Electrophoretic transfer of proteins from polyacrylamide gels to nitrocellulose sheets. Procedure and some applications. Proc. Natl. Acad. Sci. USA. 76:4350-4354.

18. Blander, S. J., R. F. Breiman, and M. A. Horwitz. 1989. A live avirulent mutant Legionella pneumophila vaccine induces protective immunity against lethal aerosol challenge. J. Clin. Invest. 83:810-815.

19. Sampson, J. S., S. P. O’Connor, B. P. Holloway, B. B. Plikaytis, G. M Carlone, and L. W. Mayer. 1990. Nucleotide sequence of htpB, the Legionella pneumophila gene encoding the 58-kilodalton ( $\mathrm{KDa}$ ) common antigen, formerly designated the $60-\mathrm{kDa}$ common antigen. Infect. Immun. 58:3154-3157.

20. Hoffman, P. S., L. Houston, and C. A. Butler. 1990. Legionella pneumophila htpAB heat shock operon:nucleotide sequence and expression of the 60-kilodalton antigen in L. pneumophila-infected Hela cells. Infect. Immun. 58:3380 3387.

21. Gabay, J. E., M. S. Blake, W. Niles, and M. A. Horwitz. 1985. Purification of the major outer membrane protein of Legionella pneumophila and demonstration that it is a porin. J. Bacteriol. 162:85-91.

22. Hoffman, P. S., C. A. Butler, and F. D. Quinn. 1989. Cloning and temperature-dependent expression in Escherichia coli of a Legionella pneumophila gene coding for a genus-common 60-kilodalton antigen. Infect. Immun. 57:17311739.

23. Shinnick, T. M., M. H. Vodkin, and J. C. Williams. 1988. The Mycobacterium tuberculosis $65-\mathrm{kD}$ antigen is a heat shock protein which corresponds to common antigen and to the Escherichia coli GroEL protein. Infect. Immun. 56:446-451.
24. Young, D. B. 1988. Structure of mycobacterial antigens. Brit. Med. Bull. 44:562-583.

25. Wagar, E. A., J. Schachter, P. Bavoil, and R. S. Stephens. 1990. Differential human serologic response to two 60,000 molecular weight Chlamydia tracho matis antigens. J. Infect. Dis. 162:922-927.

26. Morrison, R. P., R. J. Belland, K. Lying, and H. D. Caldwell. 1989. Chlamydial disease pathogenesis. The 57-KD chlamydial hypersensitivity antigen is a stress response protein. J. Exp. Med. 170:1271-1283.

27. Shinnick, T. M. 1991. Heat shock proteins as antigens of bacterial and parasitic pathogens. Curr. Top. Microbiol. Immunol. 167:145-160.

28. Jindal, S., A. K. Dudani, B. Singh, C. B. Harley, and R. S. Gupta. 1989 Primary structure of a human mitochondrial protein homologous to the bacteria and plant chaperonins and to the 65-kilodalton Mycobacterial antigen. Mol. Cell. Biol. 9:2279-2283.

29. Res, P. C. M., C. G. Schaar, F. C. Breedveld, W. van Edan, J. D. A. van Embden, I. R. Cohen, and R. R. P. de Vries. 1988. Synovial fluid reactivity against the $65 \mathrm{kD}$ heat-shock protein of mycobacteria in early onset of chronic arthritis. Lancet. ii:478-480.

30. Gaston, J. S. H., P. J. Life, P. J. Jenner, M. J. Colston, and P. A. Bacon. 1990. Recognition of a mycobacterial-specific epitope in the 65-kD heat-shock protein by synovial fluid derived T cell clones. J. Exp. Med. 171:831-834.

31. Van Eden W., J. E. R. Thole, R. Van Der Zee, A. Noordzij, J. D. A. Van Embden, E. J. Hensen, and I. R. Cohen. 1988. Cloning of the mycobacterial epitope recognized by $\mathrm{T}$ lymphocytes in adjuvant arthritis. Nature (Lond.). 331:171-173.

32. Holoshitz, J., A. Matitau, and I. R. Cohen. 1984. Arthritis induced in rats by cloned T lymphocytes responsive to mycobacteria but not to collagen type II. J. Clin. Invest. 73:211-215.

33. Munk, M. E., B. Schoel, S. Modrow, R. W. Karr, R. A. Young, and S. H. E. Kaufmann. 1989. T lymphocytes from healthy individuals with specificity to self-epitopes shared by the mycobacterial and human 65-kilodalton heat shock protein. J. Immunol. 143:2844-2849.

34. Lamb, J. R., V. Bal, P. Mendez-Samperio, A. Mehlert, A. So, J. Rothbard, S. Jindal, R. A. Young, and D. B. Young. 1989. Stress proteins may provide a link between the immune response to infection and autoimmunity. Intl. Immunol. 1:191-196.

35. Billingham, M. E. J., S. Carney, R. Butler, and H. J. Colston. 1990. A mycobacterial 65-kD heat shock protein induces antigen-specific suppression of adjuvant arthritis, but is not itself arthritogenic. J. Exp. Med. 171:339-344.

36. Van Den Broek, M. F., E. J. M. Hogervorst, M. C. J. Van Bruggen, W. Van Eden, R. Van Der Zee, and W. B. Van Den Berg. 1989. Protection against streptococcal cell wall-induced arthritis by pretreatment with $65-\mathrm{kD}$ mycobacterial heat shock protein. J. Exp. Med. 170:449-466.

37. Elias, D., D. Markovitz, T. Reshef, R. Van Der Zee, and I. R. Cohen. 1990. Induction and therapy of autoimmune diabetes in the nonobese diabetic (NOD/Lt) mouse by a $65 \mathrm{KDa}$ heat shock protein. Proc. Natl. Acad. Sci. USA. 87:1576-1580.

38. Horwitz, M. A. 1987. Characterization of avirulent mutant Legionella pneumophila that survive but do not multiply within human monocytes. J. Exp. Med. 166:1310-1328.

39. Clemens, D. L., and M. A. Horwitz. 1990. Demonstration that Legionella pneumophila produces its major secretory protein in infected human monocytes and localization of the protein by immunocytochemistry and immunoelectron microscopy. Clin. Res. 38:480A. 